\title{
Not so fast: taste stimulus coding time in the rat revisited
}

\section{Michael S. Weiss and Patricia M. Di Lorenzo*}

Department of Psychology, Binghamton University, Binghamton, NY, USA

\section{Edited by:}

Mark Laubach, The John B. Pierce

Laboratory, USA

\section{Reviewed by:}

Ranier Gutierrez, Centro de

Investigación y de Estudios

Avanzados del Instituto Politécnico

Nacional, Mexico

Jamie D. Roitman, University of

Illinois, USA

*Correspondence:

Patricia M. Di Lorenzo, Department of Psychology, Binghamton

University, Box 6000, Binghamton, NY 13902-6000, USA.

e-mail:diloren@binghamton.edu
Behavioral and electrophysiological studies suggest that rats can identify a taste stimulus with a single lick, in $<200 \mathrm{~ms}$. However, the conditions under which these conclusions were drawn varied widely across experiments. We designed a series of experiments to assess the effects of the number of licks of a tastant that are available, tastant concentration and prior learning experience on the speed with which a tastant can modify behavior. To accomplish this we tested exemplars of four basic taste qualities (quinine, $0.1 \mathrm{mM}$; $\mathrm{NaCl}, 100 \mathrm{mM}$; saccharin, $4 \mathrm{mM}$, or sucrose, $100 \mathrm{mM}$; citric acid, $10 \mathrm{mM}$ ) in rats that were conditioned to avoid quinine. Taste stimuli were available for one, two, or three licks on separate days. All tastants were presented in a randomized order interspersed with water rinse licks presented on a variable ratio schedule. A tastant-specific significant increase in the proportion of long pauses in licking following quinine presentation was defined as evidence of "behavioral identification." Rats with aversion training given three licks of all taste stimuli paused significantly more often after quinine by the fourth interlick interval, $\sim 580 \mathrm{~ms}$. Control rats showed no evidence of quinine $(0.1 \mathrm{mM})$ identification. When rats in all conditioning groups were tested with a high concentration of quinine $(10 \mathrm{mM})$, a single lick was sufficient to produce significant pausing after quinine, but not until the fourth interlick interval, i.e., $\sim 580 \mathrm{~ms}$. Testing rats with only two tastants rather than four in a session had no effect on the speed of quinine identification. Present data confirm that a single lick is sufficient for rats to identify a taste stimulus, but that additional licks occur before evidence of identification is apparent. Furthermore, learning, tastant concentration and motivation to drink can all modify the speed of behavioral identification.

Keywords: taste, identification, behavior, conditioned taste aversion, rat

\section{INTRODUCTION}

In the visual and auditory systems, rapid encoding of stimuli and decision-making is a well-known feature of neural processing. For example, there is long standing evidence that the identification of a visual or auditory stimulus can occur within $\sim 200-300 \mathrm{~ms}$ (Valls-Sole et al., 1999; Fabre-Thorpe et al., 2003; Carlsen et al., 2011). In the chemical senses, taste and olfaction, which many consider "slow" senses, there is also evidence that stimuli can be identified with similar rapidity. Fast identification of tastes and smells has a clear evolutionary advantage to an animal. That is, recognition of smells that signal danger or the taste of deadly poisons can and do trigger relatively fast evasive action while, conversely, finding, and ingesting foodstuffs speaks to the very essence of survival skills. Thus rapid encoding of taste and smell is supported by a powerful evolutionary mandate.

In rats, information about taste is obtained by licking or lapping. Although the movements that generate licking are under the control of a central pattern generator housed mainly in the lateral reticular formation (Brozek et al., 1996; Travers et al., 1997; Chen et al., 2001) several forebrain structures provide modulation (see Simon et al., 2006). Licking does not usually occur as a single event but rather in bursts called "bouts." Even a single drop of fluid will elicit a burst of licks (Hulse and Suter, 1968). Rats will also lick air (Mendelson and Chillag, 1970), suggesting that licking may be sustained by tactile feedback in the absence of fluid delivery to the mouth. The recognition of pleasant (hedonically positive) or unpleasant (hedonically negative) taste quality (sweet, sour, salty, bitter, or umami) can be assessed by stereotypical orofacial behaviors (Grill and Norgren, 1978) that can occur on the order of seconds following passive infusion of tastants to the mouth via intraoral cannulae. However, in a rat that is actively licking fluids, say from a drinking spout, the presence of a hedonically negative tastant is signaled by a sometimes rapid cessation of licking.

When discussing the time it takes to encode a taste stimulus, many investigators refer to the work of Halpern and Tapper (1971). In their classic paper on taste quality coding time, Halpern and Tapper (1971) showed that rats conditioned to avoid a $300 \mathrm{mM} \mathrm{NaCl}$ solution via irradiation withheld further responses to $\mathrm{NaCl}$ after a single lick. Based on this observation, they argued that the presence of $\mathrm{NaCl}$ was identified before a second lick was shown, i.e., within $\sim 160-200 \mathrm{~ms}$, assuming a lick rate of 5-6/s. The observation that these same rats did not stop licking when presented with sucrose provided evidence that a true quality discrimination (rather than a simple recognition of something other than water) was the basis for cessation of licking to $\mathrm{NaCl}$. In a subsequent paper, Brozek et al. (1980) further calculated the time that the tongue was in contact with the spout $(\sim 40 \mathrm{~ms})$ and the time from the initiation of a lick to its completion $(\sim 80 \mathrm{~ms})$ to conclude that the time for encoding taste quality must take place 
within $\sim 80 \mathrm{~ms}$. Collectively, these data provide compelling evidence that the neural representation of taste quality occurs during a much shorter response interval than is typically analyzed by most electrophysiologists (see Di Lorenzo and Lemon, 2001 for a discussion of this point).

It is possible that several variables in Halpern and Tapper's (1971) experiment may have speeded the recognition of $\mathrm{NaCl}$. For example, $\mathrm{NaCl}$, the conditioned stimulus (CS), was presented for $10 \mathrm{~s}$ at regular intervals, so a learned expectation may have been at play. Also, their rats were trained and tested in the same experimental chamber so the context may have enhanced the anticipation that $\mathrm{NaCl}$ would be presented. That is, the rats may have been "primed" to expect the delivery of the CS. This priming would take the form of an increase in the probability of encountering certain stimuli in particular environments and thus shift the threshold for action given even incomplete information. Working against the influence of expectation is the effect of water deprivation on performance. It is known that rats that are water deprived will accept unpalatable liquids more readily than rats that are fluid replete (Scalera, 2000). Consistent with this argument is Halpern and Tapper's (1971) observation that rats licked more than once on the first presentation of $\mathrm{NaCl}$ and it took several presentations of $\mathrm{NaCl}$ before the rats stopped licking after a single lick.

It is important to emphasize that Halpern and Tapper's (1971) argument that taste stimuli can be encoded by the information obtained in a single lick is based solely on the observation that rats paused following a single lick of the $\mathrm{CS}(\mathrm{NaCl})$. There are two points to consider about this observation. First, rats sometimes pause following any number of licks no matter what the taste stimulus. It is, therefore, important to consider pauses in the lick pattern in the context of how often they occur for the CS in relation to other taste stimuli. We address this issue here by presenting four taste stimuli of different qualities (sweet, sour, salty, and bitter) in the same session following conditioned taste aversion (CTA) training. We measured the relative frequency of pauses in the lick pattern that were $>350 \mathrm{~ms}$ since previous research has shown that a pause of this duration signaled the end of a lick bout (Hulse and Suter, 1968). Second, since, as mentioned above, it is well known that rats emit several licks for even a single drop of fluid (e.g., Hulse and Suter, 1968), exactly how many drops of fluid it takes to provide enough information for taste identification is unknown. Thus, in Halpern and Tapper's (1971) experiments, rats may have stopped licking after a single $\mathrm{NaCl}$ lick because they were naturally pausing, as they might for any other stimulus, or because a single lick provided all the information they needed to identify $\mathrm{NaCl}$ as the CS. We address this issue by varying the number of licks of each taste stimulus that are available to each rat, thereby presumably varying the amount of information that can be used for stimulus identification.

The present set of experiments was designed to test several hypotheses about taste recognition time. First, we tested the hypothesis that increasing the salience of a taste stimulus through learning would enable trained rats to "behaviorally recognize" (in this case stop licking for a certain amount of time) that stimulus with fewer licks than untrained rats. To test this, we first trained a group of rats to avoid a weak concentration of quinine in their home cage. Control groups were not trained or received the $\mathrm{CS}$ and the unconditioned stimulus $(\mathrm{LiCl})$ separated by a day. Next, all rats were tested with four different taste stimuli, plus water, in an experimental chamber designed to allow the delivery of a different tastant or water on every lick. Tastants were quinine, $\mathrm{NaCl}$, saccharin, and citric acid dissolved in distilled water. Water was also presented as a taste stimulus. Since quinine is normally avoided, we expected rats to pause when a lick elicited a delivery quinine. However, since rats will pause their licking from time to time regardless of the taste stimulus, we defined "behavioral identification of quinine" as a statistically significant increase in the proportion of pauses after licking quinine vs. all other tastants (one can make a distinction between behavioral identification and "perceptual identification" in that in the latter case an animal may perceive a stimulus but not react behaviorally to it). On separate days, rats were given tastants for a single lick, for two licks, or for three licks and the interlick intervals (ILIs) were recorded. These different conditions varied the amount of information (in the form of the amount of tastant) that was available to the rat as the basis for behavioral identification. Results showed that only conditioned rats could recognize quinine after 4 ILIs $(\sim 580 \mathrm{~ms})$, but only when given three licks of tastants. To test the effects of motivation to drink on the time and the number of licks required for behavioral identification, we analyzed the second half of each session, when the animals were partially sated. Next, to test the hypothesis that a higher concentration of quinine would speed behavioral identification, we presented a $10 \mathrm{mM}$ quinine for a single lick; all rats identified quinine, but again, only after the fourth ILI ( $\sim 580 \mathrm{~ms})$. Our third hypothesis was based on the idea that rats were taking a relatively long time to behaviorally identify quinine because the task was too difficult. That is, in Experiment 1, rats were required to pick out quinine from among an array of four different taste stimuli. To test the hypothesis that task difficulty slowed behavioral identification, we presented quinine along with one other tastant, either saccharin or sucrose. Again, no animal behaviorally identified quinine until the fourth ILI ( 580 ms).

\section{MATERIALS AND METHODS SUBJECTS}

Thirty-six male Sprague-Dawley rats weighing 280-350 g at the beginning of experiments were used. Animals were bred at Binghamton University and individually housed in clear plastic cages with a red tube for environmental enrichment. Rats were maintained on a 12-h light/dark cycle (lights on at $0700 \mathrm{~h}$ ) and room temperature was kept at $21 \pm 2^{\circ} \mathrm{C}$. Food and water were accessible according to the experimental protocol. Animal care and procedures were in accordance with the guidelines set forth by the Institutional Animal Care and Use Committee of Binghamton University.

\section{PRETRAINING}

All rats underwent a single pre-training session prior to any experimental manipulations. Rats were water deprived for $20 \mathrm{~h}$ and placed in a clear plastic testing chamber 
$(11 " \mathrm{~L} \times 81 / 4 " \mathrm{~W} \times 13 " \mathrm{H})$ housed in a soundproof melamine box $\left(26 " \mathrm{~W} \times 22 " \mathrm{H} \times 22^{\prime \prime} \mathrm{D}\right)$ with a viewing window $\left(12^{\prime \prime} \times 12^{\prime \prime}\right)$ and house light (Med Associates, Inc., St. Albans, VT). When the house light came on, $\mathrm{dH}_{2} \mathrm{O}$ was available from a lick spout; the house light remained lit until the rat licked at least 1000 times. The animal was then removed, placed back in its home cage and given free access to water.

\section{STIMULUS DELIVERY AND BEHAVIORAL TESTING}

Animals were presented with $100 \mathrm{mM} \mathrm{NaCl}(\mathrm{N}), 10 \mathrm{mM}$ citric acid (CA), $4 \mathrm{mM}$ saccharin (S), $100 \mathrm{mM}$ sucrose $(\mathrm{Su}), 0.1 \mathrm{mM}$ quinine- $\mathrm{HCl}(\mathrm{Q}), 10 \mathrm{mM}$ quinine- $\mathrm{HCl}(\mathrm{HQ})$, or $\mathrm{dH}_{2} \mathrm{O}(\mathrm{W})$ when licking. Taste stimuli were delivered through a spout in a recess at one end of the chamber. The spout consisted of an array of twelve 20-gauge stainless steel tubes housed within a larger stainless steel tube $8 \mathrm{~mm}$ in diameter. Taste solutions were held in $50 \mathrm{ml}$ tubes under pressure $(\sim 10 \mathrm{psi})$ and delivered to the lick spout through polyethylene tubing. Stimulus presentations were randomized using MedPC software (Med Associates Inc., St. Albans, VT) and stimulus delivery was controlled by solenoids (Parker Hannifin, Fairfield, NY) that delivered $12 \pm 1 \mu$ l of fluid immediately after the rat broke an infrared beam in the front of the sipper tube in the licking recess. The amount of lick-evoked fluid delivery was calibrated individually for each taste stimulus daily. Each session lasted for $30 \mathrm{~min}$.

\section{DATA ANALYSIS}

For each session, the timing of each lick was obtained from MedPC software and imported into Microsoft Excel. From these values, ILIs were calculated and became our dependent measure. In the present paradigm, rats licked regularly without pausing for many of the trials for all taste stimuli, often including quinine. So, when a rat did pause following a given stimulus presentation, the timing of that pause with respect to the first stimulus lick was comparable for all tastants. The difference between quinine and all other tastants was that quinine resulted in a larger proportion of stimulus presentations where the rat paused. Therefore, for each stimulus, the distribution of ILIs for each of six licks following the first stimulus lick was constructed in $10 \mathrm{~ms}$ bins ranging from $<90$ to $>350 \mathrm{~ms}$. Since taste stimuli were presented in a randomized order, different stimuli could be presented for different numbers of times in a session. To compare the distributions of ILIs across taste stimuli, the distribution of raw numbers of ILIs was transformed to percentages. That is, the number of licks in each time bin was divided by the total number of licks to calculate the percent of total licks per bin. As explained below, we defined behavioral identification as a significantly higher proportion of ILIs $>350 \mathrm{~ms}$ for quinine compared with the other taste stimuli and water. In effect, if a rat interrupted licking for at least $350 \mathrm{~ms}$ more often when it received quinine than when it received other tastants or water, we took that as evidence that the rat identified quinine. Six ILIs following the first stimulus lick were analyzed to ensure that we could detect any evidence of behavioral recognition of quinine before a different stimulus was presented. Statistical analyses for each experiment are described in the appropriate Results sections. All analyses were performed on SPSS version 18.0 and Microsoft
Excel 2010. Statistical significance was defined as $\alpha=0.05$. Means are expressed as average \pm standard error of the mean (SEM) where appropriate.

\section{EXPERIMENT 1}

\section{CONDITIONED TASTE AVERSION TRAINING}

After pre-training, rats were adapted to a deprivation schedule in their home cages in which they had access to $\mathrm{dH}_{2} \mathrm{O}$ for $10 \mathrm{~min}$ every afternoon (1400-1410 h) and for $1 \mathrm{~h}$ (1600-1700 h) every evening. The amount of water intake during the $10 \mathrm{~min}$ exposures was recorded to the nearest $\mathrm{ml}$. After at least 5 days on this schedule, rats were given a saline injection (150 $\mathrm{mM} \mathrm{NaCl}$; $1 \%$ b.w., i.p.) following the $10 \mathrm{~min}$ water access for 3 days.

Rats were then divided into a saline treated $(n=5)$, unpaired control $(n=6)$, and paired aversion $(n=5)$ group. On acquisition day, all rats were given access to $0.1 \mathrm{mM}$ quinine- $\mathrm{HCl}$ instead of water for the $10 \mathrm{~min}$ exposure session. This was followed by a saline injection (150 mM NaCl, 1\% b.w., i.p.) for the saline control group (Control) and a $\mathrm{LiCl}$ injection (150 $\mathrm{mM} \mathrm{LiCl}, 1 \%$ b.w., i.p.) for the paired aversion group (Paired Q). The unpaired control group (Unpaired) received a saline injection $(150 \mathrm{mM} \mathrm{NaCl}$, $1 \%$ b.w., i.p.) after exposure to quinine and given the normal $10 \mathrm{~m}$ exposure to water the next day followed by a $\mathrm{LiCl}$ injection (150 mM, 1\% b.w., i.p.).

At the end of Experiment 1, rats were again given a $10 \mathrm{~min}$ exposure to $0.1 \mathrm{mM}$ quinine in their home cage to verify that rats in the Paired Q group retained a conditioned aversion to quinine. Results showed that the Paired Q group drank less quinine than they did on the conditioned aversion acquisition day compared to the combined Control and Unpaired groups $(5.6 \pm 0.84 \mathrm{ml}$ for Control and Unpaired vs. $2.8 \pm 0.96 \mathrm{ml}$ for Paired $\mathrm{Q}, p<0.01$ ).

\section{TESTING}

\section{Experiment 1A. Effects of learning on speed of recognition}

After a recovery period of 2 days, animals were water deprived for $20 \mathrm{~h}$ before behavioral testing. Rats were then placed in the testing chamber; the house light was turned on and stayed on throughout the session to indicate that fluid was available from the lick spout. Taste stimuli were presented according to one of three paradigms: one stimulus lick (one-lick), two consecutive stimulus licks (twolick), or three consecutive stimulus licks (three-lick). Figure 1 illustrates the progression of tastants and rinse licks during a session for all three paradigms. In each paradigm, N, CA, S, Q, or W were available at the lick spout for blocks of one, two, or three licks respectively. Stimuli were presented in random order. Separating each stimulus block were five $\mathrm{dH}_{2} \mathrm{O}$ rinse licks, with each rinse lick presented on a variable ratio 5 (VR5) schedule following each stimulus block presentation. That is, each of five $\mathrm{dH}_{2} \mathrm{O}$ rinse licks was separated by 4-6 "dry" licks where no fluid was presented when the rat licked the spout. Following these rinse licks, the next taste stimulus was presented for one, two, or three licks, according to the paradigm for that day. Each animal experienced all three paradigms on separate days in a pseudorandomized order.

\section{Experiment 1B. Effects of concentration on speed of recognition}

Following the completion of Experiment 1A, all rats were tested with $\mathrm{N}, \mathrm{S}, \mathrm{CA}, \mathrm{W}$, or HQ (a high concentration of quinine) in a 


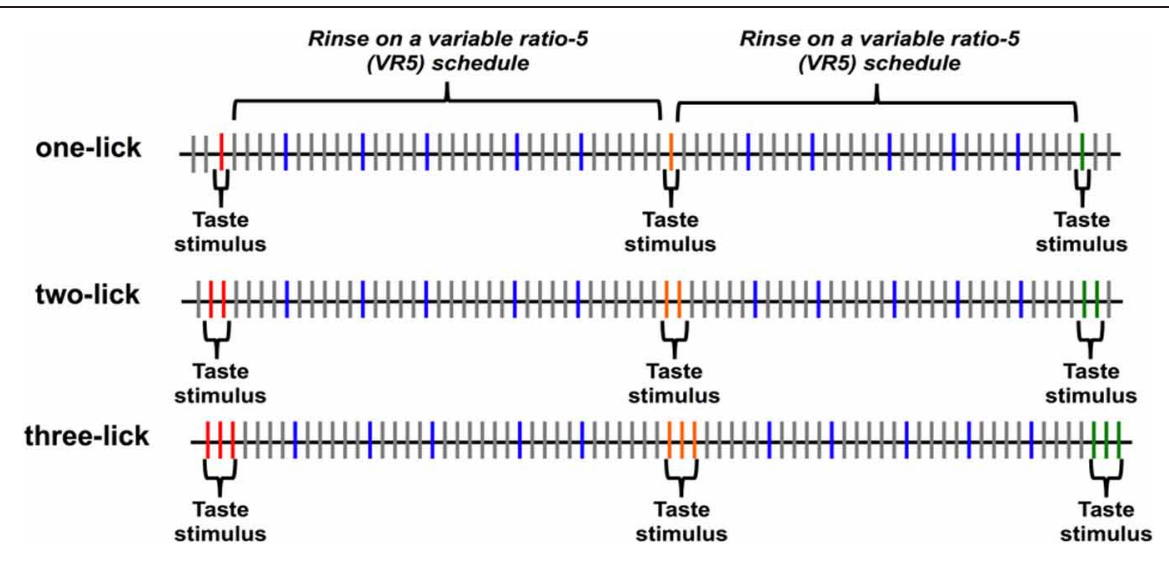

FIGURE 1 | Diagram of the stimulus presentation paradigm. Taste stimuli were presented for one, two, or three licks depending on the session,

followed by five water rinse licks, with each rinse lick on a variable ratio 5
(VR5) schedule. Each lick is symbolized by a vertical line; licks that resulted in a tastant or rinse delivery are symbolized by colored lines; licks that resulted in a dry (unreinforced) lick are symbolized by gray lines. one-lick paradigm as in Experiment 1A. That is, each taste stimulus was presented in a randomized order for one lick separated by five $\mathrm{dH}_{2} \mathrm{O}$ licks presented on a VR5 schedule (see Figure 1). This procedure was designed to test whether a higher concentration of quinine would affect the speed of behavioral identification of quinine.

\section{RESULTS AND DISCUSSION}

\section{Experiment 1A. Effects of learning on speed of recognition}

Figure 2 shows the distribution of ILIs in all groups when they received three stimulus licks. ILIs following the first through the sixth licks are shown. This corresponds with a lick rate of $\sim 7$ licks/s. For all taste stimuli, the distribution of ILIs has a clear mode at $\sim 145 \mathrm{~ms}$ regardless of which tastant they received (see Brozek et al., 1980). However, in the later licks (ILI 5-6) it is evident that there are more long $(>350 \mathrm{~ms}$ ) ILIs when quinine was presented than there were for the other tastants. Such disruptions of the normal lick pattern presumably originate from identification and/or avoidance of quinine. Since the task required a comparison of taste stimuli in order to identify quinine, we defined the selective emergence of these long ILIs as evidence of behavioral identification of quinine. In subsequent analyses, we estimate the time for behavioral identification of quinine by the ILI number where the proportion of ILIs $>350 \mathrm{~ms}$ is significantly larger than this proportion for all other tastants and water. We then multiply the ILI number by $145 \mathrm{~ms}$, the median of the modes of the ILI distributions across all conditions (see Figure 2). We are aware that different rats in different conditions lick at different rates so that this value is intended as an estimate rather than an exact value.

Results showed that, following CTA training, animals in the Paired Q group could behaviorally identify (and avoid) quinine (the CS) by the fourth ILI $(\sim 580 \mathrm{~ms})$ but only when given three consecutive quinine licks. When given only two stimulus licks, rats in the Paired Q group took six ILIs ( $870 \mathrm{~ms})$ to identify/avoid quinine. Animals in the Control or Unpaired groups showed no evidence of behavioral identification of

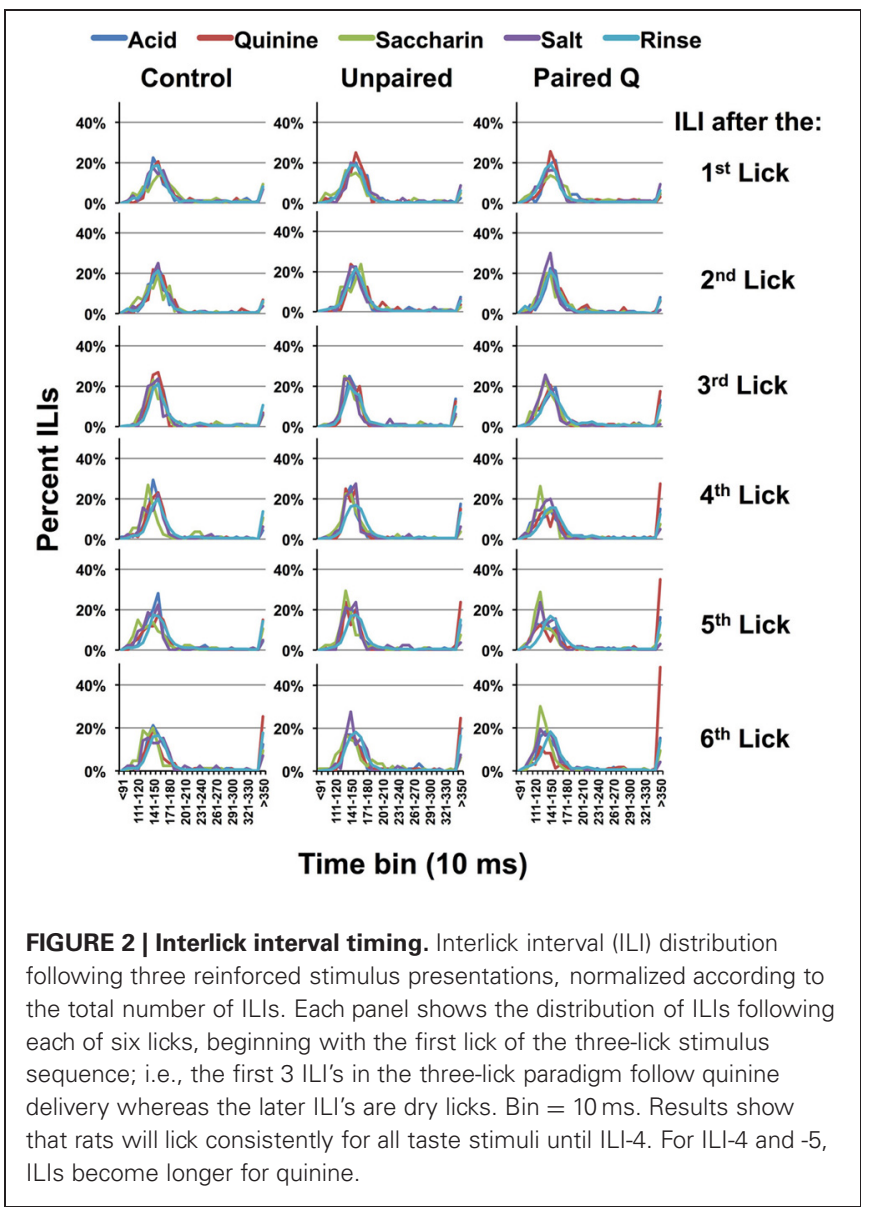

quinine, under any test condition. Collectively, these results showed that rats that learned to avoid a moderately weak concentration of quinine can behaviorally identify it faster when more information (i.e., more stimulus licks) is available. Rats that were not trained to avoid quinine showed no evidence of behavioral identification, likely due to the low salience of 
this concentration of quinine compared to the salience of the other tastants, as well as a high motivation to obtain fluid.

Figure 3 shows the percent of ILIs $>350 \mathrm{~ms}$ following each of six ILIs beginning with the first stimulus lick presentation in all conditions in all groups. It is clear that there was no evidence of behavioral identification of quinine in the Control, Unpaired, or Paired Q groups when rats were presented with one stimulus lick of each tastant. However, Paired Q rats that received two consecutive licks of taste stimuli in each stimulus block paused after licking quinine more than they did after licking any other tastants including water (planned contrasts of quinine vs. all other stimuli, $p<0.001$, at ILI-5. However, this was not significant when comparing across groups; planned contrasts against Control and Unpaired groups, $p=0.13$ and $p=0.09$, respectively). Rats trained to avoid quinine showed evidence of behavioral identification of quinine at ILI-4 (planned contrasts at ILI-4 in the three lick paradigm, $p<0.05)$ when allowed three consecutive taste stimulus licks.

Statistical analyses verified that only the Paired Q group showed evidence of behavioral identification of quinine, OneWay ANOVA, $\left[F_{(1,13)}=5.731, p<0.05\right]$. Using a four-way mixed model ANOVA revealed that there were main effects for

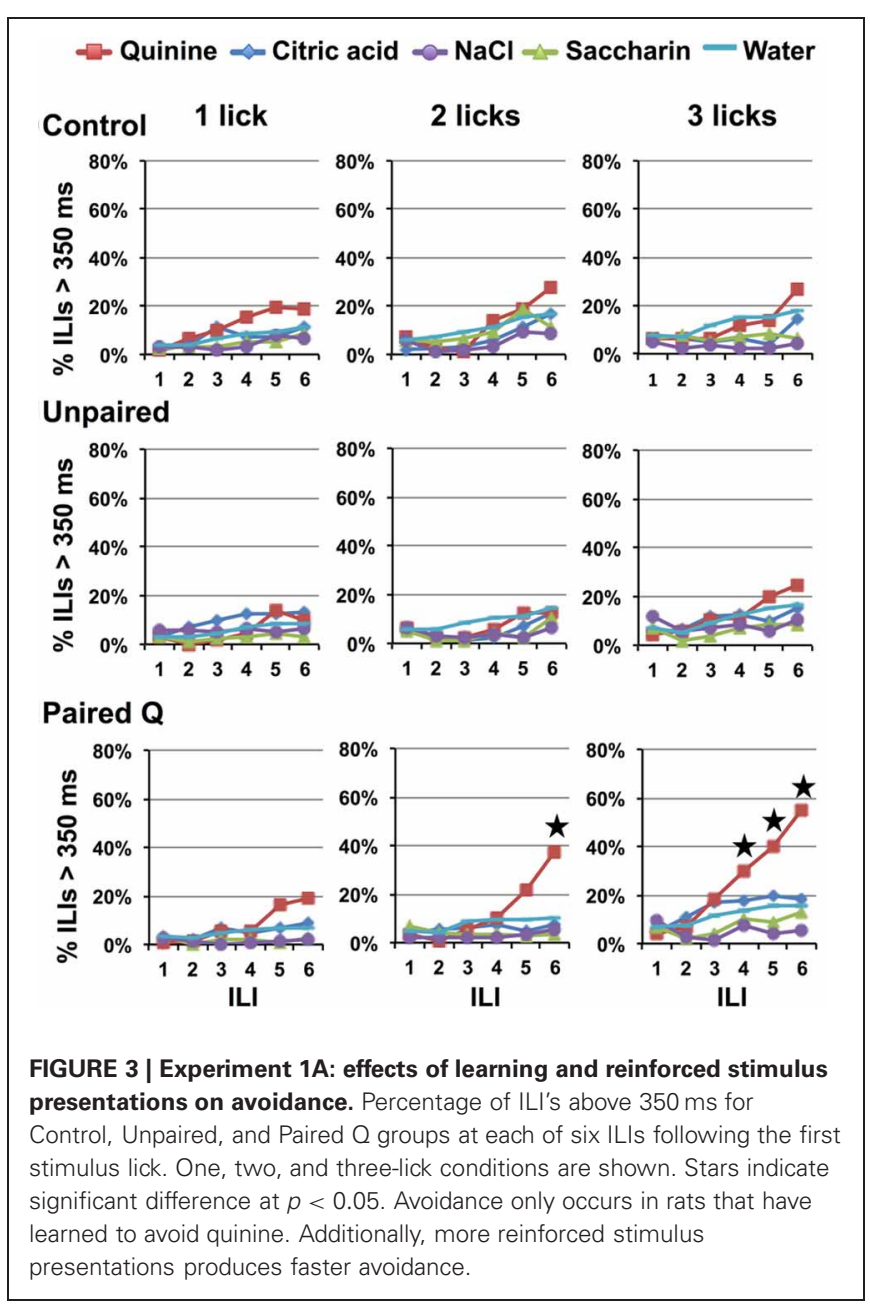

taste stimulus, $\left[F_{(4,52)}=10.731, p<0.001\right]$, number of stimulus licks, $\left[F_{(2,26)}=5.993, p=0.007\right]$, and ILI number, $\left[F_{(5,65)}=\right.$ $52.122, p<0.001]$, as well as second order interactions for taste stimulus by paradigm, $\left[F_{(8,104)}=2.383, p<0.05\right]$, taste stimulus by ILI, $\left[F_{(20,260)}=17.065, p<0.001\right]$, paradigm by ILI, $\left[F_{(10,130)}=2.224, p<0.05\right]$, and a third order interaction of taste stimulus by paradigm by ILI, $\left[F_{(40,520)}=1.604, p<0.05\right]$.

Since all rats were water deprived before testing, they were motivated to drink regardless of the inherent negative hedonic value of the stimulus. Relatedly, Scalera (2000) has shown that thirsty rats will tolerate more aversive taste stimuli. This may have lengthened the time it took for rats to stop licking quinine even though they may have perceptually identified it. In addition, since we averaged across rats in each group, it was possible that some individual rats could behaviorally identify quinine faster than ILI-4. To answer these questions, we first divided each testing session in half according to the number of licks for each individual animal. In the first half of the session, the rats were more thirsty and more motivated to drink compared with the second half of the session when they had already consumed $\sim 4 \mathrm{ml}$ of fluid. To determine whether any animals could behaviorally identify quinine faster than ILI-4, we plotted the data from individual animals. Results are shown in Figure 4. It can be seen that a single rat in the Paired Q group tested in the three-lick paradigm showed evidence of behavioral identification of quinine $(>50 \%$ of all ILIs that were $>350 \mathrm{~ms}$ ) at ILI-3 or $\sim 435 \mathrm{~ms}$. To summarize, these data show that a low motivation to drink combined with a history of a CTA to quinine enabled behavioral identification of quinine within $\sim 435 \mathrm{~ms}$ in the three-lick paradigm in one rat.

\section{Experiment 1B. Effects of concentration on speed of recognition}

Increasing the concentration of quinine to $10 \mathrm{mM}$ produced robust behavioral identification of quinine in all groups even when given a single lick of each stimulus (one-lick paradigm, see Figure 1). However, there was no effect of a higher quinine concentration on the ILI at which behavioral identification of quinine became significant. Figure 5 shows that a HQ produced significantly more long pauses in licking at ILI-4 ( $\sim 580 \mathrm{~ms})$, compared to all other stimuli $(p<0.001$, results are collapsed across all groups).

All animals in the one-lick paradigm that received a HQ along with the other taste stimuli and water behaviorally identified quinine, but only after four licks, i.e., three additional licks following the stimulus presentation. Interestingly, as Figure 5 indicates, the proportion of lick pauses associated with quinine was significantly higher at ILI-4 compared that shown at ILI-4 in Experiment 1A (one stimulus presentation of a lower concentration), planned contrast of $\mathrm{Q}$ and HQ at ILI-4, $p<0.001$. A Two-Way RM-ANOVA revealed a significant main effect of concentration $\left[F_{(1,13)}=51.10, p<\right.$ $0.001]$ as well as a significant main effect of ILI $\left[F_{(5,65)}=\right.$ 98.963, $p<0.001]$. These data suggest that a single lick provided enough information to support behavioral identification of quinine. Nevertheless, rats continued to lick (dry or water rinse licks) four more times before stopping. It is unclear from these data whether this reflects an inability to stop licking 


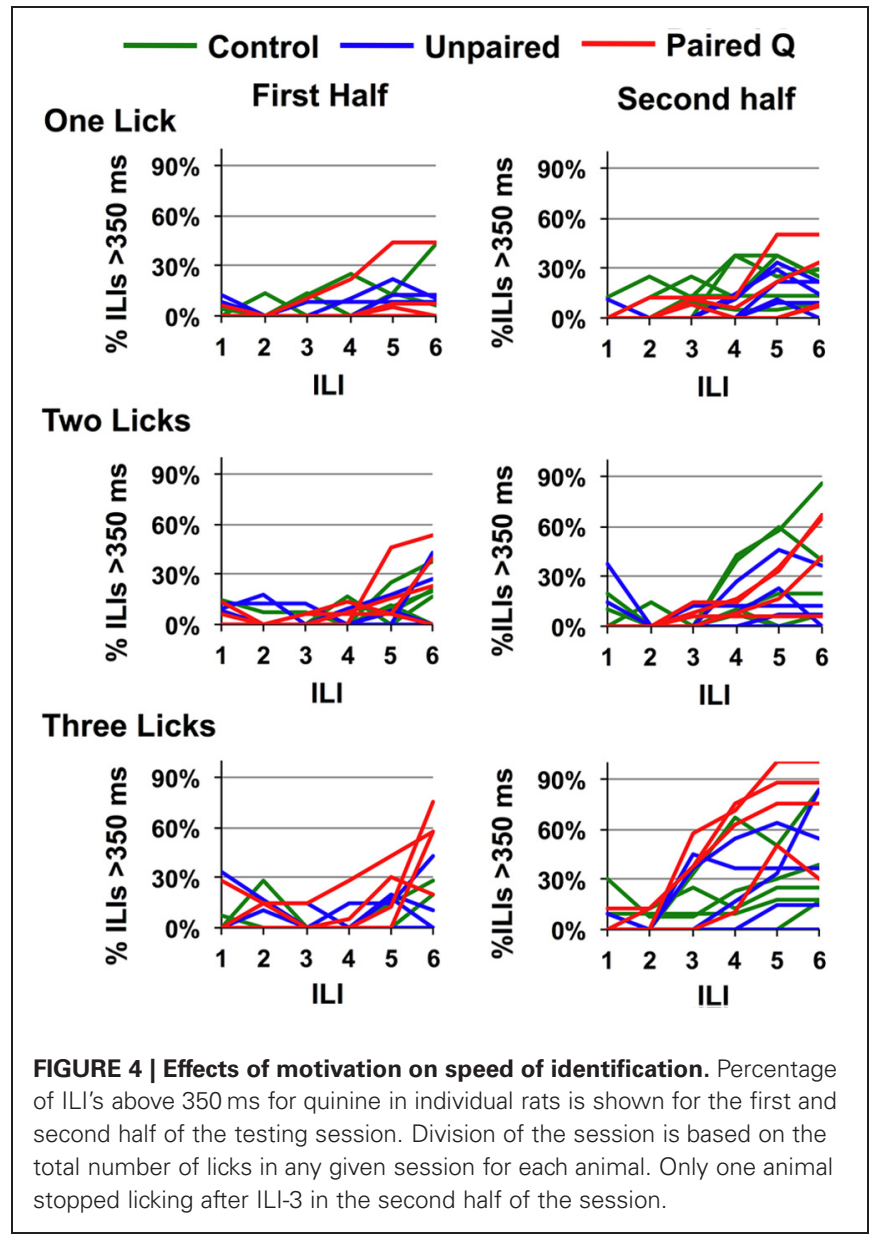

once licking was started, or whether the neural representation was insufficient to support the behavioral identification of quinine.

In sum, Experiment 1 showed that the number of stimulus licks, CTA learning and stimulus intensity can all affect the speed with which behavioral identification of quinine becomes apparent. Specifically, more stimulus licks speeded behavioral identification in rats that had learned to avoid quinine, but did not reduce behavioral identification time any more than did the presentation of a higher quinine concentration. In fact, none of the conditions that were tested produced evidence of behavioral identification before the fourth ILI ( $580 \mathrm{~ms})$. It is likely that the enhanced salience of the quinine afforded by each of the experimental manipulations was responsible for the speeded behavioral identification.

It was a bit surprising that animals that did not learn an aversion to quinine did not show any evidence of a disruption in the regularity of their lick pattern after the presentation of quinine. One factor may have been the fact that quinine was presented along with three other tastants plus water, so the task of behaviorally recognizing quinine was too difficult. To test this hypothesis, we presented another group of rats with only $\mathrm{Q}$, $\mathrm{S}$, and water, interspersed with $\mathrm{dH}_{2} \mathrm{O}$ rinses in Experiment 2. Both the standard $(\mathrm{Q})$ and high (HQ) concentrations were tested.

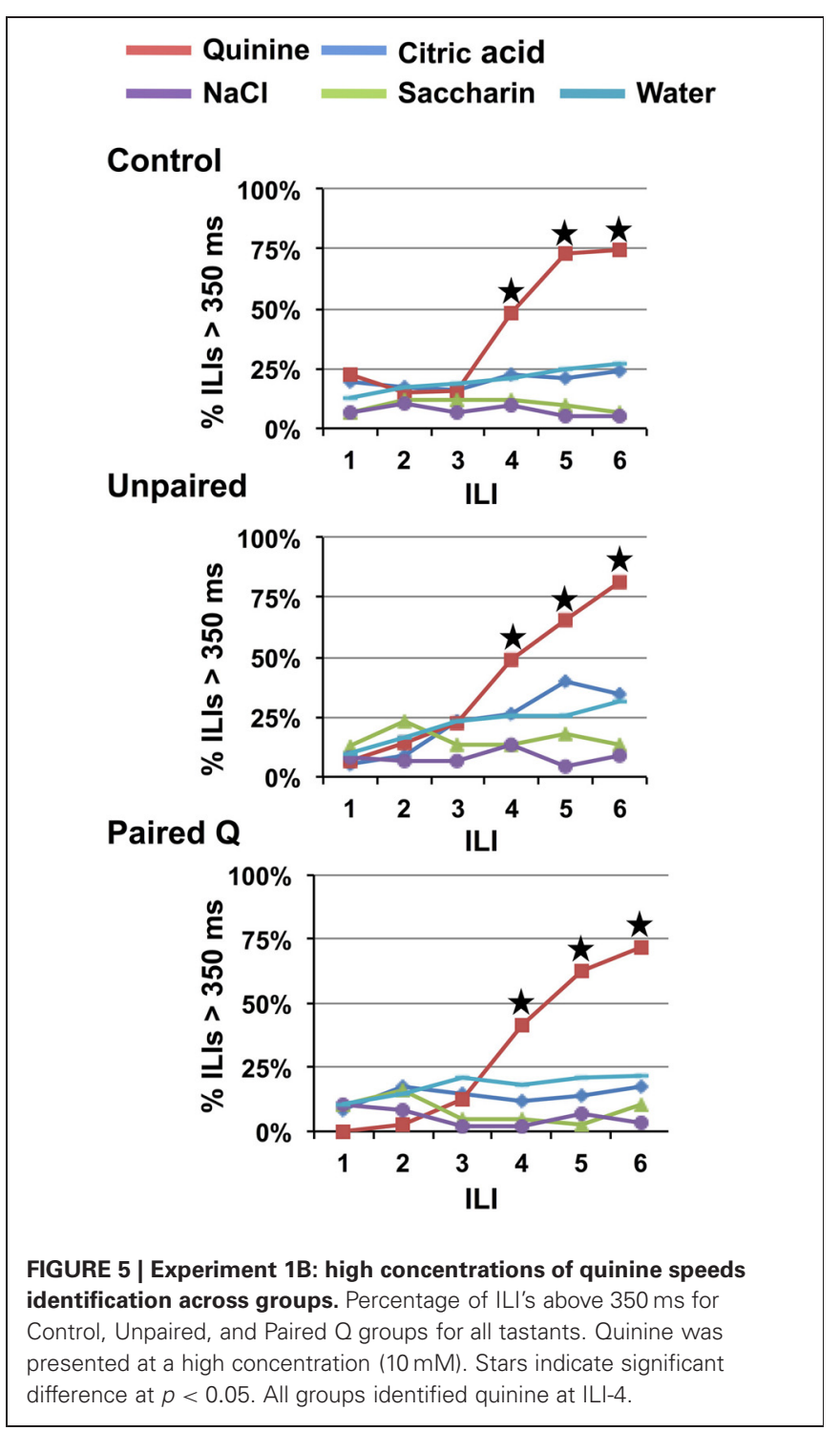

\section{EXPERIMENT 2}

\section{EXPERIMENT 2A}

Following pretraining to lick water, animals $(n=12)$ were water deprived for $20 \mathrm{~h}$. For behavioral testing, animals received one stimulus lick of $\mathrm{Q}, \mathrm{S}$, or $\mathrm{W}$ separated by $\mathrm{dH}_{2} \mathrm{O}$ rinses presented on a VR5 schedule. Stimuli were presented in a randomized order. The ratio of $\mathrm{Q}$ to $\mathrm{S}$ to $\mathrm{W}$ delivery was 1:1:2.

\section{EXPERIMENT 2B}

Animals from Experiment 2A were given a hydration day and then deprived of water $20 \mathrm{~h}$ before being tested with HQ, S, and W. The ratio of HQ to $S$ to $W$ delivery was 1:1:2.

\section{RESULTS AND DISCUSSION}

Simplifying the behavioral identification task by reducing the number of stimulus choices did not reduce recognition time. As in Experiment 1, rats that were presented with one stimulus lick showed no evidence of behavioral identification of quinine. 
Figure 6A indicates that there is no evidence of behavioral identification of quinine at any of the ILIs, $\left[F_{(2,22)}=0.76, p=0.48\right]$. Testing a HQ along with saccharin and water produced evidence of behavioral identification of quinine at ILI-6 ( $\sim 870 \mathrm{~ms})$, also consistent with data from Experiment 1. However, Figure 6B also shows that both saccharin and to some extent water, also produced relatively high (but not statistically reliable) proportions of long pauses in the lick pattern at around ILI-3. This can be due to multiple factors. For example, one explanation might be that the increase in the concentration of quinine in Experiment 2B as well as the reduction in number of stimuli available may have enhanced the bitter "second-taste" of saccharin (see Stewart and Krafczek, 1988). We, therefore, decided to test rats with a choice of sucrose, quinine, or water in Experiment 3.

\section{EXPERIMENT 3}

\section{EXPERIMENT 3A}

After pre-training, animals $(n=8)$ were water deprived for $20 \mathrm{~h}$. For behavioral testing, animals received one stimulus lick of $\mathrm{Q}$, $\mathrm{Su}$, or $\mathrm{W}$, presented in a randomized order, separated by $\mathrm{dH}_{2} \mathrm{O}$ rinses presented on a VR5 schedule. The ratio of $\mathrm{Q}$ to $\mathrm{Su}$ to $\mathrm{W}$ delivery was 1:1:2.

\section{EXPERIMENT 3B}

Animals from Experiment 3A were given a hydration day and then deprived of water $16-20 \mathrm{~h}$ before being retested with $\mathrm{HQ}$, $\mathrm{Su}$, and $\mathrm{W}$, presented in randomized order, separated by $\mathrm{dH}_{2} \mathrm{O}$
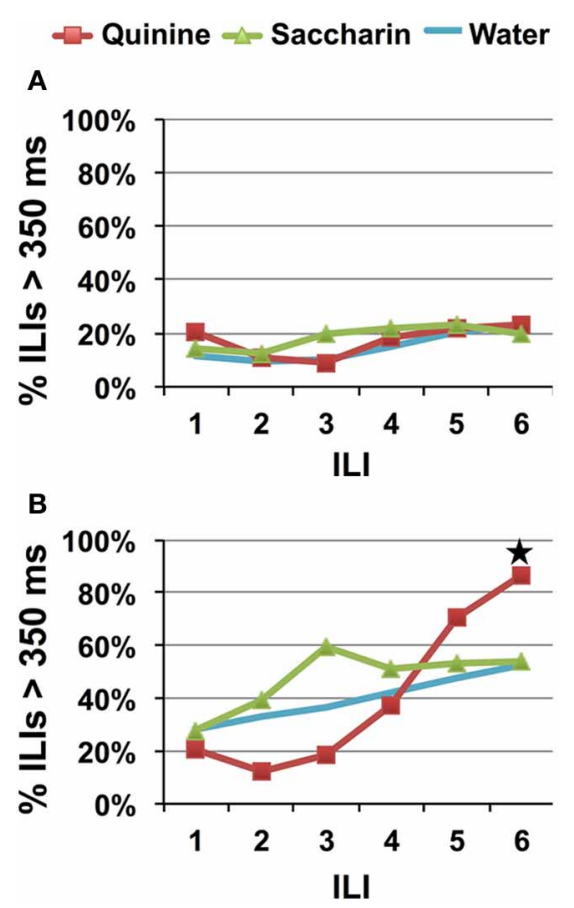

FIGURE 6 | Speed of quinine identification when only saccharin and quinine were presented. Percentage of ILI's above $350 \mathrm{~ms}$. Each stimulus was presented for a single lick. All rats were untrained. (A) Quinine was presented at $0.1 \mathrm{mM}$. (B) Quinine was presented at $10 \mathrm{mM}$. Star indicates significant difference at $p<0.05$. rinses presented on a VR5 schedule. The ratio of HQ to Su to W delivery was 1:1:2.

\section{RESULTS AND DISCUSSION}

Using sucrose instead of saccharin did not affect the speed of quinine avoidance/identification, for a low concentration of quinine (Figure 7A, planned comparison of sucrose vs. quinine, $p=$ 0.395). A significant avoidance to $H Q$ was not apparent until ILI-5 ( $725 \mathrm{~ms})$, planned contrast of HQ vs. W and Su, $p<$ 0.03 . Replacing saccharin with sucrose attenuated the increase in avoidance at ILI-3 seen with saccharin when paired with a HQ (Figure 7B).

In general, Experiments 2 and 3 showed that reducing the number of stimuli to which a rat is exposed does not speed taste recognition time. Figure 8 illustrates this point. This figure shows that avoidance/recognition of quinine progresses over time at the same rate whether rats are presented with four tastants or two.

\section{DISCUSSION}

Results presented here speak directly to the question of how much time and information is needed to identify a taste stimulus in rats. Our data showed that rats can identify a HQ if given only a single lick, but it took $\sim 580 \mathrm{~ms}$ before they reacted appropriately. At a more moderate quinine concentration, a CTA to quinine was necessary for rats to identify quinine. Trained rats also needed two or three licks of quinine to do so. The fastest that any rat tested under these conditions could identify quinine was after
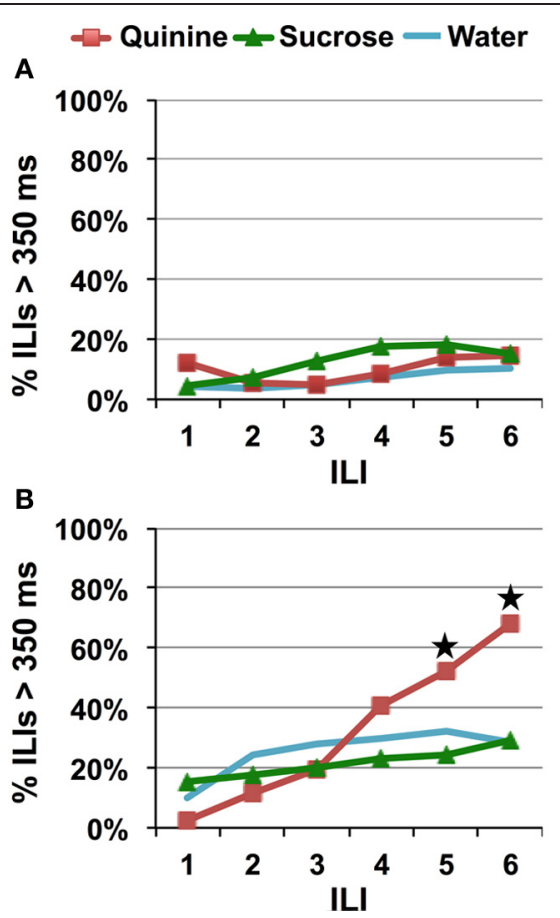

FIGURE 7 | Speed of quinine identification when only sucrose and quinine were presented. Percentage of ILI's above $350 \mathrm{~ms}$. Each stimulus was presented for a single lick. All rats were untrained. (A) Quinine was presented at $0.1 \mathrm{mM}$. (B) Quinine was presented at $10 \mathrm{mM}$. Stars indicate significant difference at $p<0.05$. 


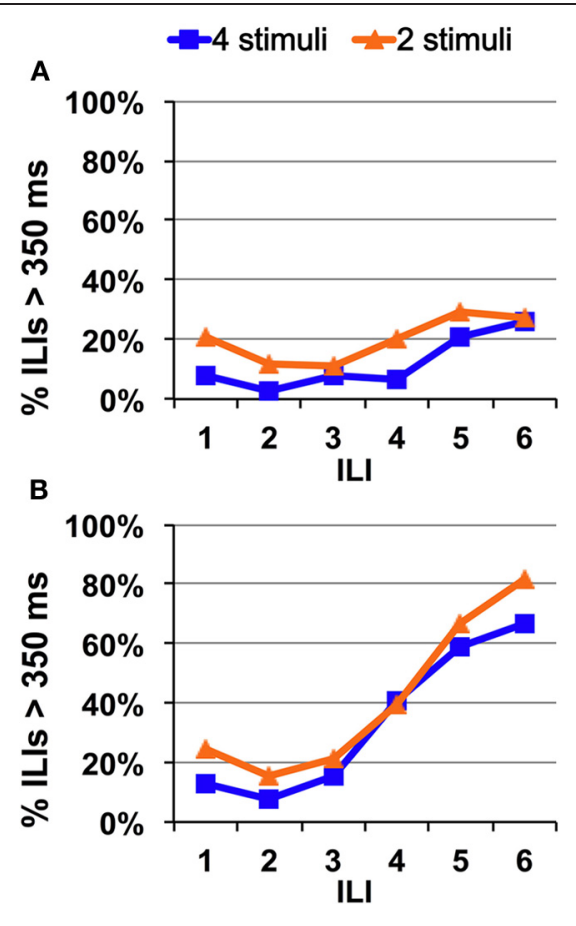

FIGURE 8 | Direct comparison of speed of quinine identification when two or four tastants are presented in a single session. Percentage of ILI's above $350 \mathrm{~ms}$. All rats were untrained. (A) Quinine was presented at $0.1 \mathrm{mM}$. (B) Quinine was presented at $10 \mathrm{mM}$.

three licks, $\sim 435 \mathrm{~ms}$, in the second half of the test session when motivation to drink was low. Even when the identification task was simplified by increasing the probability of encountering quinine on any given lick, avoidance/identification still took at least $\sim 580$ ms. Collectively, these data document the involvement of a variety of factors that can influence the time for behavioral identification of a taste stimulus. These include motivation to drink, learning, stimulus concentration and amount of information available (number of stimulus licks) upon which to base a decision. Further, present data suggest that the "time window" during which the neural representation of a taste is fully formed (and should thus be the focus in electrophysiological studies) may be a flexible function of several variables that can either speed or decelerate tastant identification.

There are reports in the literature, both behavioral and electrophysiological, that appear to be at odds with the conclusions presented here; however, these discrepancies are more apparent than real. For example, Gutierrez et al. (2010) have shown that rats trained in a go-no-go behavioral task can identify a taste stimulus, by sampling with a single lick, i.e., within $<145 \mathrm{~ms}$. However, this observation occurred after the rats were highly trained, suggesting that more training in the present study, i.e., more quinine-LiCl pairings might speed quinine identification. Certainly the present data suggest that the two choice paradigm in Gutierrez et al.'s report (vs. several additional tastants from which to choose) would likely not speed recognition. Some electrophysiological studies of taste-responsive cells in the gustatory cortex have also pointed to the time frame of a single lick for taste identification. Stapleton et al. (2006) described responses that occurred within $90 \mathrm{~ms}$ of a lick that could discriminate among taste stimuli. Further, Stapleton et al. (2007) showed that ensembles of taste-responsive cells in the gustatory cortex of awake, behaving rats could identify a taste stimulus within $150 \mathrm{~ms}$. While it is possible that rats can accomplish this task, present results suggest that this happens only in rats with intensive training. More consistent with present findings is the work of Katz et al. (2001) who showed that taste-specific neural activity in the gustatory cortex does not appear until at least $200 \mathrm{~ms}$ following the infusion of a taste stimulus into the mouth and that hedonically related cortical activity does not appear until $\sim 1 \mathrm{~s}$.

It is possible, perhaps likely, that rats may have internally identified quinine, but may not have been able to stop licking because of the time needed to pause the central pattern generator that generates the licking pattern (see Travers et al., 1997). The fact that rats in the high quinine concentration, one lick condition kept licking for three additional dry licks before pausing is consistent with this notion. Alternatively the rats may have been motivated to continue licking in order to acquire a water rinse and/or a more palatable stimulus. In either case, the neural events that underlie tastant identification are necessarily layered on top of the decision-making process that would affect movement (see Gold and Shadlen, 2007). In fact, several investigators have shown that the time between tastant presentation and the initiation of movement indicative of identification in taste discrimination tasks is at least 1 s (MacDonald et al., 2009; Gutierrez et al., 2010; Yoshida and Katz, 2011).

If one considers decision-making and the sensory neural representation as inextricable, there are several questions that arise related to the time course for encoding taste stimuli. For example, one might ask what the taste system is capable of when aided by both high expectation (e.g., few choices) and motivation (e.g., water deprivation, learning). In that sense, one is asking about the limits of the decision process under optimal conditions, i.e., what is the fastest time that an animal can react appropriately to a taste stimulus. Here the word "appropriately" implies that some information upon which to base a decision has already been conveyed by the sensory neural representation. Alternatively, one might ask what occurs when there is little prior experience and when the consequences of a wrong decision are neutral. Such an evaluation might reflect a somewhat different mode of sensory processing in that there is no urgency about making a decision. In that case, the neural representation may be more fully elaborated before an action is taken. Thus, when the stakes are high, decisions may necessarily be based on less information, but when the stakes are low, more information is collected before a decision is made. By allowing an animal a relatively unlimited amount of time to collect information, the study of encoding of a stimulus under conditions of low motivation and little prior experience may reveal the time course of the full elaboration of the neural representation of a stimulus.

\section{ACKNOWLEDGMENTS}

We would like to thank Andrew Fooden and Alexander Everhart for their technical contributions to this project. This work was supported by NIDCD grant RO1-DC006914 to Patricia M. Di Lorenzo. 


\section{REFERENCES}

Brozek, G., Welzl, H., Klimenko, V., Buresova, O., and Bures, J. (1980). Role of licking and associated changes in excitability of brain centers in the processing of taste information. Neurosci. Behav. Physiol. 10, 106-112.

Brozek, G., Zhuravin, I., Megirian, D., and Bures, J. (1996). Localization of the central rhythm generator involved in spontaneous consummatory licking in rats: functional ablation and electrical brain stimulation studies. Proc. Natl. Acad. Sci. U.S.A. 93, 3325-3329.

Carlsen, A., Lam, M., Maslovat, D., and Chua, R. (2011). Reaction time effects due to imperative stimulus modality are absent when a startle elicits a pre-programmed action. Neurosci. Lett. 500, 177-181.

Chen, Z., Travers, S., and Travers, J. (2001). Muscimol infusions in the brain stem reticular formation reversibly block ingestion in the awake rat. Am. J. Physiol. Regul. Integr. Comp. Physiol. 280, 1085-1094.

Di Lorenzo, P. M., and Lemon, C. H. (2001). "Methodological considerations for electrophysiological recording and analysis of tasteresponsive cells in the brain stem of the rat," in Methods in Chemosensory Research, eds S. A. Simon and M. A. L. Nicolelis (New York, NY: CRC Press), 293-324.

Fabre-Thorpe, M., Delorme, A., Marlot, C., and Thorpe, S. (2003). A limit to the speed of processing in ultra-rapid visual categorization of novel natural scenes. J. Cogn. Neurosci. 13, 171-180.

Gold, J. I., and Shadlen, M. N. (2007) The neural basis of decision making. Annu. Rev. Neurosci. 30, 535-574.

Grill, H., and Norgren, R. (1978). The taste reactivity test. I. Mimetic responses to gustatory stimuli in neurologically normal rats. Brain Res. 153, 263-279.

Gutierrez, R., Simon, S. A., and Nicolelis, M. A. (2010). Lickinginduced synchrony in the taste reward circuit improves cue discrimination during learning. J. Neurosci. 30, 287-303.

Halpern, B., and Tapper, D. (1971). Taste stimuli: quality coding time. Science 171, 1256-1258.

Hulse, S. H., and Suter, S. (1968). Onedrop licking in rats. J. Comp. Physiol. Psychol. 66, 536-539.

Katz, D. B., Simon, S. A., and Nicolelis, M. A. (2001). Dynamic and multimodal responses of gustatory cortical neurons in awake rats. J. Neurosci. 21, 4478-4489.

MacDonald, C. J., Meck, W. H., Simon, S. A., and Nicolelis, M. A. (2009). Taste-guided decisions differentially engage neuronal ensembles across gustatory cortices. J. Neurosci. 29, 11271-11282.

Mendelson, J., and Chillag, D. (1970). Schedule-induced air licking in rats. Physiol. Behav. 5, 535-537.

Scalera, G. (2000). Taste preference and acceptance in thirsty and dehydrated rats. Physiol. Behav. 71, 457-468.

Simon, S., de Araujo, I. E., Gutierrez, R., and Nicolelis, M. A. (2006). The neural mechanisms of gustation: a distributed processing code. Nat. Rev. Neurosci. 7, 890-901.

Stapleton, J. R., Lavine, M. L., Wolpert, R. L., Nicolelis, M. A., and Simon, S. A. (2006). Rapid taste responses in the gustatory cortex during licking. J. Neurosci. 26, 4126-4138.

Stapleton, J. R., Lavine, M. L., Nicoleilis, M. A., and Simon, S. A. (2007). Ensembles of gustatory cortical neurons anticipate and discriminate between tastants in a single lick. Front. Neurosci. 1, 161-174. doi: 10.3389/neuro.01.1.1. 012.2007

Stewart, C., and Krafczek, S. (1988). The taste characteristics of sodium-saccharin in the rat: a re-examination of the dual taste hypothesis. Chem. Senses 13, 205-212.

Travers, J., Dinardo, L., and Karimnamazi, H. (1997). Motor and premotor mechanisms of licking. Neurosci. Biobehav. Rev. 21, 631-647.

Valls-Sole, J., Rothwell, J., Goulart, F., Cossu, G., and Munoz, E. (1999). Patterned ballistic movements triggered by a startle in healthy humans. J. Physiol. 516, 931-938.

Yoshida, T., and Katz, D. B. (2011). Control of prestimulus activity related to improved sensory coding within a discrimination task J. Neurosci. 31, 4101-4112.

Conflict of Interest Statement: The authors declare that the research was conducted in the absence of any commercial or financial relationships that could be construed as a potential conflict of interest.

Received: 14 February 2012; accepted: 16 May 2012; published online: 31 May 2012.

Citation: Weiss MS and Di Lorenzo PM (2012) Not so fast: taste stimulus coding time in the rat revisited. Front. Integr. Neurosci. 6:27. doi: 10.3389/fnint 2012.00027

Copyright (c) 2012 Weiss and Di Lorenzo. This is an open-access article distributed under the terms of the Creative Commons Attribution Non Commercial License, which permits non-commercial use, distribution, and reproduction in other forums, provided the original authors and source are credited. 